and well worth reading. Although it is a bestseller in Australia, it is not readily available in the United States. However, it can be obtained through the publisher or online via several Australian bookstores. At the time of this writing, the publisher has no plans for widespread distribution outside Australia. The book is very informative about a subject that is all but unknown in the modern hospitals to which most of us are accustomed. The suffering caused by vaginal fistula injuries is unfortunate because it could be prevented, yet this book can spread the message that help is available to instigate change and provide a better tomorrow for so many girls and women in the third world.

Dennis Wales, MD Houston, TX, USA

Manual of Travel Medicine and Health, 2nd edition Robert Steffen, MD; Herbert DuPont, MD; and

Annelies Wilder-Smith, MD

London, UK: BC Decker Inc, 2003

US \$59.95, 628 pages, softcover

This wonderful little $(6 \times 4 \times 1$ inch $)$ book is a great resource for travelers and the health care providers who counsel or treat them. Although it is written for a medical audience, even the interested layperson will find its concise nontechnical approach quite readable.

The book is divided into 4 major parts: "The Basics," "Infectious Health Risks and their Prevention," "Non-Infectious Health Risks and Their Prevention," and "Diagnosis and Management of Illness After Return or Immigration." Several appendices follow these sections, which are all written in a "just the facts, ma'am" style that befits the book's small format. Interspersed throughout are tables that, for the most part, clarify the text and provide a quick visual reference; however, occasionally they are too data intense and confusing. There are no figures other than several maps, and all is in black and white.

The book comes with a mini CD-ROM in a plastic envelope on the inside front cover. The $\mathrm{CD}$ is the book in a PDF format and makes searching for desired material much easier, but if left in place it stiffens the cover and makes the book more difficult to read.

The first section of the book comprehensively handles the preparation that should occur before traveling. The authors have obviously been in the travel-medicine business; their insights are impressive. Certain segments address the standard issues of what to expect in terms of health risks when going to different parts of the globe: food safety, water purification, an overview of immunizations, and accident prevention. There are also many issues that would not have come immediately to mind, such as migration medicine, travel concerns of athletes, how to advise the last-minute traveler, and the Incapacitated Passenger Handling Form for airlines. There is even advice on how to clean dentures without contracting traveler's diarrhea: "soak them in beer." The guidance on how to advise prospective travelers with preexisting medical conditions is very useful.

The second chapter, on infectious health risks, is a litany of the usual suspects from anthrax to yellow fever. Expanded sections cover hepatitis, HIV, malaria, and other ailments. The references and recommendation are current and even include SARS.

The third chapter, on noninfectious concerns, includes overviews of animal bites, health risks that may put off scuba diving, jet lag, and ciguatera. The emphasis is on prevention of problems rather than on treatment, so the management of pulmonary emboli is listed only as "state of the art procedures." Curiously, the chapter does not mention lightning, which is a worldwide hazard.

The provider who may not specialize in travel medicine may find the final chapter the most interesting. Here we find out how to deal with the returning voyager who is ill. Focusing on 3 complaints - fever, rash, diarrheaand 1 lab finding - eosinophilia - the authors guide the clinician through algorithms and tables that can lead to appropriate diagnosis and treatment. The approach to a returning expatriate who may not be ill but may be harboring an occult pathogen can easily be expanded to the immigrant population.

This book concludes with several appendices listing vaccination requirements for various countries and malaria hot spots. Lists of resources are also provided: websites, organizations for further reference, and texts (although my personal favorite, Paul S. Auerbach's Wilderness Medicine, is left out) are up-to-date and wide ranging.

Overall, the Manual of Travel Medicine and Health is a must-have reference both for the home library and, because of its small size, for backpacks or luggage. I will look forward to the next update.

John R. Saucier, MD

Yarmouth, ME, USA

\section{Tropical Medicine and Parasitology, 5th edition}

Wallace Peters and Geoffrey Pasvol

St Louis, MO: Mosby, 2002

US \$64.92, 334 pages, softcover

Like a red wine that improves with age, the fifth edition of Tropical Medicine and Parasitology is refined, updated, and seemingly more pertinent than ever. In a 